\title{
Impact of Nematode Heterodera avenae Wollenwebwer, 1924 (Heteroderidae) attack on cereal yields in the region of Tiaret (Algeria)
}

\author{
Labdelli Fatiha", Bousmaha Fatma², Adamou Djerbaoui Malika', Bouchenafa Nadia', Oulbachir Karima' \\ \& Laouidj Aicha' \\ ${ }^{1}$ Agrobiotechnology Laboratory, Ibn Khadoun University, Tiaret, Algeria \\ ${ }^{2}$ Hygienique and Pathological Animal Laboratory Veterinary School, Ibn khaldoun University, Tiaret, Algeria \\ ${ }^{*}$ Corresponding author, email: fleurs_jasmin@yahoo.fr
}

\begin{abstract}
The cyst nematode Heterodera avenae Wollenweber, 1924 (Heteroderidae) is an obligate endoparasite of grasses. It is the most studied and most damaging nematode known for more than a century. The study of the distribution of the $H$. avenae cyst nematode was carried out on some plots of cereal-oriented municipalities in the Tiaret region to assess the infestation levels of the plots in order to study the impact of the nematode infestation on cereal yields. Spearman's test was used, which allowed us to study the correlation between the degree of infestation and cereal yields, particularly wheat, barley and oats. The plots of the communes surveyed are all infested by H. avenae with different levels of infestation except the plots of the town of Sebaine and Mahdia where the infestation is practically non-existent $(0$ cysts $/ 100 \mathrm{~g}$ of soil). The correlation is negative between the degree of infestation and the yield $(r=-0.06)$, the yields of hard wheat are low when the degree of infestation is high. Soft wheat and barley yields are negatively correlated with respectively, $r=-0.26$ and $r=-0.27$, therefore, heavy infestations of the nematode lead to a decrease in yield. Unlike other cereal species, the correlation is positive with the degree of infestation $(r=0.18)$, so the infestation of the nematode did not greatly influence oat yields. Oats are a tolerant species for nematode attack in relation to wheat and barley that have recorded decreases in yields. Unlike the three previous crop types, oats stand out for their tolerance to this parasite.
\end{abstract}

KEY WORDS Cereals; correlation; nematode; Tiaret; yield.

Received 03.06.2020; accepted 10.10.2020; published online 30.12.2020

\section{INTRODUCTION}

The main crops in Algeria are cereals. Their importance is justified through a wide use of their products that are the most consumed. With a population in perpetual growth, the low yields may not satisfy the National needs despite subsidies from the state.

At the level of the high plateaus, grain farming is the most practiced particulary in the region of
Tiaret formerly called the attic of Algeria. Among the obstacles that impede the farming of cereals, we can mention the climatic vagaries (the variation in temperature and low rainfall).

Added to this, the bio-aggressors which weaken the productions of cereals, including the nematodes pests. The losses of agricultural productions due to nematodes have been estimated at $10 \%$ of the world production (Whitehead, 1998). 
This species was found in many countries like Australia, South Africa, Japan, and most European countries (Kort, 1972), India (Sharma \& Swarrup, 1984), West Asia and Pakistan (Sikora, 1988) Saudi Arabia (Ibrahim et al., 1999). In North Africa, Heterodera was found in Algeria by Scotto La Massesse (1961), Lamberti et al. (1975) and Mokabli et al. (2001), in Morocco by Franklin (1951) and Rammah (1994), and in Tunisia by Ritter (1959); most of the works devoted to it are limited to Europe, Australia, and India (Swarup \& SosaMoss, 1990).

In Algeria, the losses caused by this nematode are not well known. Indeed, the lack of data on this species and its losses justify the choice of the topic of the study, which focuses on the cyst nematode $H$. avenae in the region of Tiaret.

The present work is devoted to the study of the distribution of the nematode to cysts $H$. avenae on some plots of certain common to grain vocation of the region of Tiaret to assess the degrees of infestation of parcels in order to study the impact of the infestation of the nematode on the yields of cereals.

\section{MATERIAL AND METHODS}

Nematological analysis is based on a sample which consists of the search and counting of nematode in the cyststate. Extraction of cysts has been done with the help of Fenwick methods (Fenwick, 1940) modified by Oostenbrink (1950) (see also Sosa-Moss, 1966). Regions cultivated in cereals have been chosen according to the infestation level and after theprevious investigation. Samples consist to remove quantities of ground with depth from 10 to $40 \mathrm{~cm}$. This has been done at a rectangular level area of $12 \mathrm{~m}^{2}(2.40 \times 5 \mathrm{~m})$.

The extraction apparatus of cysts is constituted by a body measuring $30 \mathrm{~cm}$ height, $15 \mathrm{~cm}$ diameter at the bottom and around of $9 \mathrm{~cm}$ at the top. Apparatus's bottom is constituted by an oblique plan sloping to an orifice allowing emptying, is surmounted by a funnel supporting a kitchen colander with stitches of $1 \mathrm{~mm}$, and the upper part of the apparatus body is rounded with a sloping gutter that allows the water contained in the cysts to flow out.

A sifter of $250 \mu \mathrm{m}$ to gather afterwards cysts and certain organic fragments. According to Sosa-Moss
(1966), the functioning principle of Fenwick apparatus is founded on floating and density of cysts more or less dry according to the water.

Density scale is used as follows: Dry cyst $<$ water (1) <nematode (1.08-1.09) < wet cyst (1.18 $-1.22)<$ high density solution $<$ mineral material.

Container is full of water; we put down withered ground in the stitched colander of $1 \mathrm{~mm}$ which retains the biggest items while thin particles and cysts are pushed away by the water jet; clays, thin organic fragments and cysts, floating by impulse of water current, are carried away into the gutter by overflowing of the suspension which flows out on a sifter of $250 \mu \mathrm{m}$ between stitches; this sifter collects only cysts and some fragments. The part of suspension retained on the sifter of $250 \mu \mathrm{m}$ is gathered in blotting paper under a funnel which releases excess water. With help of a double magnifying glass, cysts are harvested by a brush or by a fine needle.

\section{RESULTS}

The study conducted at the level of a few towns in the region of Tiaret reveals the degrees of various infestation ranging from the total absence of the nematode to infestations that largely exceed the threshold of harmfulness (Table 1).

The attack of the nematode affects the cytology and the physiology of the plant. This has a direct impact on the development of the plant or even on plant yields.

The yields recorded are presented in Table 2 .

To be able to know the impact of the attack of the nematode on the yields of grain we have used the test of Spearman (Table 3).

\section{DISCUSSION}

The degrees of the studied plots infestation are heterogeneous and vary considerably from one town to another. At the level of the explored towns, degrees of infestations are divided into three levels:

1) first level: the town where the infestation is zero: Sebaine and Mahdia following the total absence of the cyst nematode $H$. avenae.

2) second level: towns where the infestation is low, does not exceed the threshold of harmfulness: Rahouia,Tiaret. 


\begin{tabular}{|l|c|c|l|}
\hline Common & $\begin{array}{l}\text { Degree of infestation } \\
\text { Cyst number/100 } \\
\text { g soil }\end{array}$ & $\begin{array}{l}\text { Degree of infestation } \\
\text { Number of L2/1 } \\
\text { g soil }\end{array}$ & Repair (Rivoal et al., 1980) \\
\hline Dahmouni & 15 & 39.39 & heavily infested >10L2/g soil \\
\hline Frenda & 13 & 29.72 & heavily infested >10 The2/g soil \\
\hline Ain El Heddid & 10 & 21.93 & heavily infested >10L2/g soil \\
\hline Mechraasfa & 8 & 11.41 & heavily infested >10L2/g soil \\
\hline Sougueur & 6 & 8.41 & Moderately infested 10 L2 /g soil \\
\hline Tiaret & 3 & 6.41 & Moderately infested 10 L2 /g soil \\
\hline Rahouia & 3 & 4.41 & Moderately infested 10 L2 /g soil \\
\hline Mahdia & 0 & 0 & free absence of L2 /1 G Soil \\
\hline Sebaine & 0 & 0 & free absence of L2 /1 G Soil \\
\hline
\end{tabular}

Table 1. Repair of Commons explored depending on the degree of infestation (number of cysts/100g and number of L2/g soil).

\begin{tabular}{|c|c|c|c|c|c|}
\hline \multirow[b]{2}{*}{ Common } & \multicolumn{4}{|c|}{ Performance $\mathrm{qx} / \mathrm{ha}$} & \multirow[b]{2}{*}{$\begin{array}{c}\text { Average yield } \\
\mathrm{qx} / \mathrm{ha}\end{array}$} \\
\hline & Hard wheat & Soft wheat & Barley & Oats & \\
\hline Dahmouni & 15.75 & 13.69 & 15.00 & 12.00 & 14.97 \\
\hline Frenda & 13.85 & 14.67 & 15.00 & 13.00 & 14.42 \\
\hline Ain El Heddid & 13.33 & 13.65 & 14.32 & 13.00 & 13.64 \\
\hline MechraaSfa & 23.20 & 19.33 & 20.00 & 21.00 & 23.43 \\
\hline Sougueur & 12.86 & 14.01 & 15.63 & 8.00 & 13.44 \\
\hline Tiaret & 16.84 & 16.30 & 16.00 & 12.00 & 16.30 \\
\hline Rahouia & 23.18 & 18.00 & 22.00 & 13.00 & 22.87 \\
\hline Mahdia & 11.67 & 14.83 & 15.79 & 10.00 & 13.58 \\
\hline Sebaine & 12.89 & 14.44 & 14.87 & 10.00 & 13.46 \\
\hline
\end{tabular}

Table 2. Yields recorded in the countryside

\begin{tabular}{|c|c|c|c|c|c|}
\hline Species & Hard wheat & Soft wheat & Barley & Oats & Average \\
\hline Correlation & -0.06 & -0.26 & -0.27 & 0.18 & -0.16 \\
\hline
\end{tabular}

Table 3. Correlation between the infestation and the performance.

3) third level: towns where the infestation is strong, far exceeding the threshold of harmfulness: Dahmouni, Frenda, Ain El Heddid, Mechraasfa and Sougueur.

The test of Spearman which has allowed us to study the correlation between the degree of infestation and the yields recorded of different cereals shows us the following.

The explored towns plots are all infested by $H$. avenae with a different degrees of infestation with 
the exception of the plots in the town of Sebaine and Mahdia or the infestation is virtually non-existent ( 0 cysts $/ 100 \mathrm{~g}$ of soil).

\section{Yields in hard wheat}

The correlation is negative between the degree of infestation and the performance $(r=-0.06)$, yields are low when the degree of infestation is high (Fig. 1).

The region of Dahmouni is the most heavily infested with a degree of infestation of 15 cysts / $100 \mathrm{~g}$ of soil, the performance in hard wheat is of 15.75 $\mathrm{qx} / \mathrm{ha}$. This degree has been reported by other authors such as: Smaha et al. (2009) and Labdelli et al. (2017). On the contrary, the town of Rahouia presents a higher performance with $23.18 \mathrm{qx} /$ ha since the degree of infestation is low: 3 cysts $/ 100$ $\mathrm{g}$ of soil.

This could be due to the sensitivity of the hard wheat to the attack of the nematode $H$. avenae. Therefore, the hard wheat is a favorable host for this dreaded pest, as studied and confirmed by Sanchez et al. (1985).

\section{Yields in common soft wheat}

The yields of common soft wheat and the degrees of infestation are negatively correlated $(\mathrm{r}=$ -0.26). The performance decreases when the degree of infestation increases, therefore the heavy infestations significantly affect the yields of this type of culture.

For the region of Tiaret, a low level infestation ( 3 cysts / $100 \mathrm{~g}$ of soil) was recorded with a yield of $16.30 \mathrm{qx} / \mathrm{ha}$.

The yields decrease if the infestation is higher, as it has been reported in the town of Frenda: the high infestation (13cysts/100g of soil) causes a decrease in the performance (14.67 qx/ha).

\section{Barley yields}

The correlation is negative $(r=-0.27)$ between the degree of infestation and the performance. Therefore, the heavy infestations result in a decrease in performance.

For the region of Rahouia, with an infestation degree of 3 cysts $/ 100 \mathrm{~g}$ of soil, so the performance of the barley reached $22 \mathrm{qx} / \mathrm{ha}$, by contrast, the re- gion of Ain el Heddid, with a degree of infestation of 10 cysts $/ 100 \mathrm{~g}$ of soil, the performance becomes lower with $14.32 \mathrm{qx} / \mathrm{ha}$. We can say that the Barley is a sensitive species to the attack of $H$. avenae.

\section{Yields of oats}

Unlike the other species of cereals, the correlation is positive with an infestation degree of $r=$ 0.18 , so the infestation of the nematode has not influenced the yields of oats largely.

Yields in the different municipalities are closer even if infestations become higher for example: in the town of Dahmouni with a degree of infestation of 15 cysts/100 $\mathrm{g}$ of soil, the performance is 12 $\mathrm{qx} / \mathrm{ha}$. Similarly, for the municipalities of Tiaret, Rahouia, the degree of infestation is 3 cysts $/ 100 \mathrm{~g}$ of soil for each; the yields are around the $12 \mathrm{qx} / \mathrm{ha}$ of the town of Dahmouni which is heavily infested with respectively 12 and $13 \mathrm{qx} / \mathrm{ha}$.

In Northern Europe, Eastern oats are considered as favorable host for the development of the nematode, whereas in Southern Europe the wheats are the most damaged due to the coincidence of the development cycle of the wheats with the winter activity of the nematode in these regions (Rivoal \& Riviere, 1989).

So we can say that the oats with positive correlation is a species tolerant to the attack of the nematode compared to wheat and barley that have registered declines in yields.

Unlike the three types of previous crops, oats is distinguished by its tolerance to this parasite.

\section{CONCLUSIONS}

Among the factors that reduce the yields of cereals in Algeria we can mention the cyst nematode of grain called Heterodera avenae, that occupies an important place prominently in view of the losses caused by this parasite. In the course of the present study undertaken in the region of Tiaret, the study of the impact of the infestation of $H$. avenae on yields has attracted the attention.

The prospecting of grain parcels in the region of Tiaret shows that the degrees of infestations registered by this nematode are variables. Apart from the regions of Mahdia and Sebaine where the nematode is completely absent, the regions of Dahmouni, 


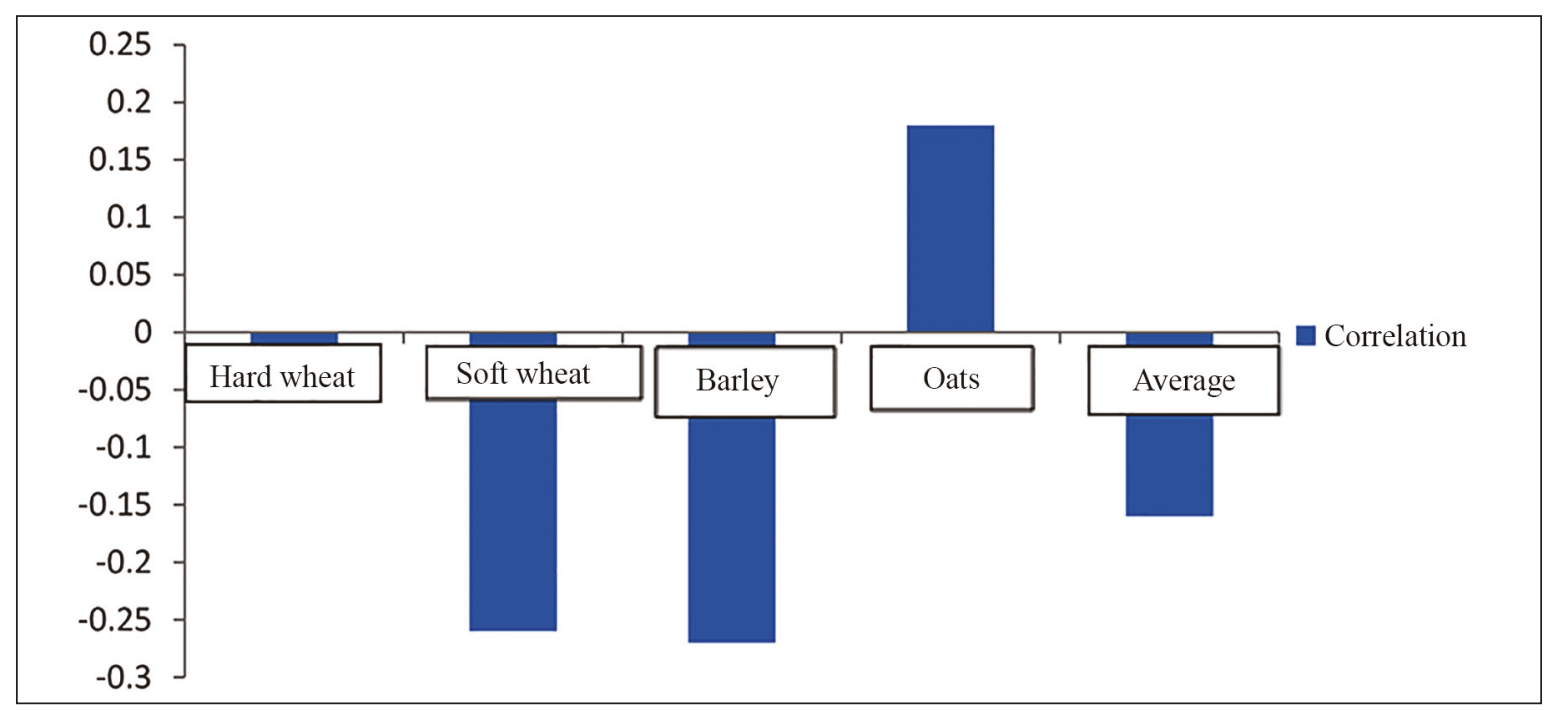

Figure 1. Histogram of the correlation between the infestation and yields.

Frenda, Ain El Heddid, MechraaSfa, SougueurTiaret, Rahouia present high degrees of infestations. Yield reductions are reported on the productions of the common wheat and barley which showed a negative correlation with the infestations. On the contrary the oats are tolerant to the attack of the nematode compared to other species of cereal.

The fight against $H$. avenae remains difficult because of the high costs of chemicals. This directs the fight against this nematode toward preventive methods by the intervention of cultivation techniques (choice of resistant varieties) or the use of an intensive system with a fallow (year by year) or an adequate rotation.

These degrees of infestation are due mainly to the monofarming practiced.

The varietal resistance is currently one of the tracks the most interesting for the fight against bioaggressors. The present study must be continued by taking into consideration the role of the Technical Itinerary: date of planting, the work of the soil and the crop rotation on the intensity of the infestations of the nematode in the soil.

\section{REFERENCES}

Fenwick D.W., 1940. Methods for the Recovery and Counting of Cysts of Heterodera schachtii from Soil. Journal of Helminthology, 18: 155-172. http://dx.doi. org/10.1017/S0022149X00031485
Franklin M.T., 1951. The cyst-forming species of Heterodera. Commonwealth Agricultural Bureaux, Farnham Royal, UK.

Ibrahim A.A.M., Alhazmi A.S., Alyhia F.A. \& Alderfasi A.A.,1999. Damage Potential and Reproduction of Heterodera avenae On Wheat and Barleyn under Saudi Field Conditions. Nematology, 1: 625-630.

Kort J., 1972. Nematode diseases of cereals of temperate climates. In: J.M. Webster (Ed.), Economic Nematology. Academic Press, London, UK, 97-126 pp.

Labdelli F., Adamou Djerbaoui M., Oulbachir K., Allal A., 2017. Behavior of cereal's varieties in the presence of Heterodera avenae Woll. (Heteroderidae, Tylenchida) cyst nematode in Tiaret area (Algeria). Journal of Fundamental and Applied Science, 9: 1378-1394.

Lamberti F., Greco N. \& Zaouchi H., 1975. Etude sur les nématodes chez les palmiers dattiers et autres cultures importantes en Algérie. Bulletin Phytosanitaire de la F.A.O, $23: 156-161$.

Mokabli A., Valette S. \& Rivoal R., 2001. Différentiation de quelques espèces de nématodes à kystes des céréales et des graminées par électrophorèse sur gel d'acétate de cellulose. Nematologia Mediterranea, 29: 103-108.

Oostenbrink M., 1950. Het aardappelaaltje (Heterodera rostochiensis Wollenweber), cen gevaarlijke parasiet voor de eenzijdige aardappelcultuur. Versl. PIZiekt. Dienst Wageningen, 115: 1-230.

Rammah A., 1994. Cereal cyst nematode (Heterodera avenae) in Morocco Arab and Near East Plant. Protection News letter, 19: 40.

Ritter M., 1959. Contribution à l'étude des nematodes phytoparasites de la Tunisie. Les Annales INRA, Tunisie, 32: 53-78. 
Rivoal R. \& Riviere J.M., 1989. Etude du profil cultural de deux sites, l'un infesté, l'autre non, par Heterodera avenae Woll.: conséquences sur le développement radiculaire du blé tendre d'hiver. France. Agronomie, 9: 719-728.

Sanchez A., Sacristan J.C. \& Bello A., 1985. Estudio de varied ades de cereales resistantes al nematodo Heterodera avenae Woll. Spain. Anales de edafologia y Agrobiologia, 44: 169-173.

Scotto La Massese C.,1961. Aperçu sur les problèmes posés par les nématodes phytoparasites en Algérie. Journées d'études et d'informations, Versaille, pp 83 109.

Sharma S.B. \& Swarup G., 1984. Cyst forming nematodes of India New Delhi. Ind Cosmopolitan Publication, 1: 150.

Sikora R.A., 1988. Plant parasitic nematodes of wheat and barley in temperature and temperate semi-arid regions - a comparative analysis. In: Saxena M.C.,
Sikora R.A. \& Srivastava J.P. (Eds.) Nematodes parasitic to cereals and legumes in temperate semi-arid regions, pp. 46-48. Aleppo, Syria, ICARDA

Smaha D., Hamroun O. \& Mokabli A., 2009. Soil temperature and hatching of Heterodera avenae in Algeria. Proceeding of First work shop of the international cyst nematode, initiative 21-23 october 2009, Antalya Turkey, pp. 130-131.

Sosa-Moss C., 1966. Contribution à l'étude d'un nématode phytoparasite Heterodera avenae Wollenweber. Thèse PhD, Docteur sciences naturelles, faculté des sciences de l'Université de Paris, France, 149 pp.

Swarup G. \& Sosa-Moss C., 1990. Nematode parasites of cereals. In: Luc M., Sikora R.A. \& Bridge J. (Eds.), Plant parasitic nematodes in subtropical and tropical agriculture, pp. 109-136. Wallingford, UK, CAB International.

Whitehead A.G., 1998. Plant nematode control. CAB International, Wallingford, UK. 